\title{
VERIFICAÇÃO DA EFICIÊNCIA DO SISTEMA DE DRENAGEM URBANA DE ÁGUAS PLUVIAIS EM ÁREA DE OCUPAÇÃO ESPONTÂNEA
}

Eduarda Izabelly Soares Ribeiro- eduardaizabelly@ hotmail.com Universidade Federal do Pará

Fábio Sergio Lima Brito - fabio.lima.ufpa@gmail.com Universidade Federal do Pará

Ana Paula Gomes Mendonça -anapaulagomesmendonca03@gmail.com Universidade Federal do Pará

Juliana Maia Duarte - duartemaiajuliana@gmail.com

Universidade Federal do Pará

Karla Karoline Leite do Rosário - karlaleite93@ gmail.com

Universidade do Estado do Pará

Rafaela Caroline Barros Silva - barrosrc15@gmail.com

Universidade Federal do Pará 


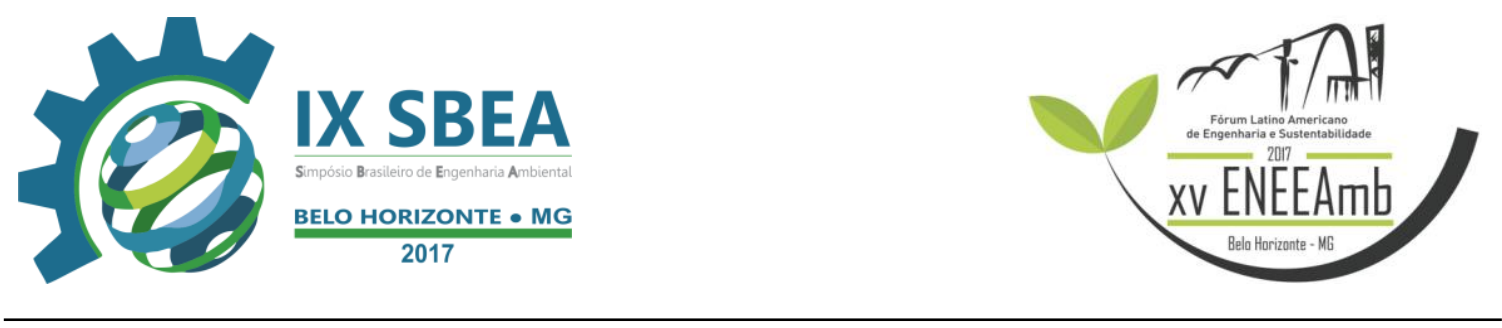

\section{RESUMO}

O sistema de drenagem urbana mostra-se uma importante obra de saneamento básico, pois além do manejo das águas pluviais ele tem a finalidade de prevenir alagamentos e inundações, propiciando um ambiente salubre a população. Nessa perspectiva, o presente trabalho tem por objetivo avaliar a eficiência do sistema de drenagem urbana em uma área de ocupação espontânea, por meio, das condições estruturais do sistema e relacionar sua interferência com a saúde pública dos moradores de um bairro de Ananindeua-PA. Os métodos de pesquisa compreendem: levantamento bibliográfico, aplicação de questionários e verificação dos elementos operacionais de microdrenagem mediante a visitas in loco na área de estudo. Os resultados apontaram insuficiência em quantidade e qualidade dos dispositivos de microdrenagem que apresentaram diversos problemas tais como: bocas de lobo sem tampa, entupidas e desmoronadas. Ademais, a ausência de uma gestão adequada e o incorreto gerenciamento das águas pluviais tem colocado em alerta a saúde dos moradores que por diversas vezes entram em contato com água contaminada devido o déficit da prestação do serviço.

Palavras Chave: Microdrenagem, Águas pluviais, Saúde Pública.

\section{INTRODUÇÃO}

No Brasil a maioria das cidades sofre com problemas de alagamentos, inundação, cheia, decorrente de uma série de fatores, dentre eles: o crescimento urbano das cidades brasileira e uso desordenado das áreas de escoamento natural tem provocado impactos significativos à população e ao meio ambiente (ALMEIDA \& COSTA, 2014; MANUAL DE DRENAGEM URBANA, 2005).

Nesse sentido, os problemas são desencadeados ainda, principalmente pela forma como as cidades se desenvolvem: falta de planejamento, controle do uso do solo, ocupação de áreas de risco e sistemas de drenagem inadequados (MANUAL DE DRENAGEM URBANA, 2005 a). Evidenciando assim, a precariedade nos serviços de saneamento básico no pais.

Dentre os fatores que dificultam o desenvolvimento harmônico da cidade, destacase o processo de ocupação espontânea. Tal processo leva a uma excessiva extensão do 


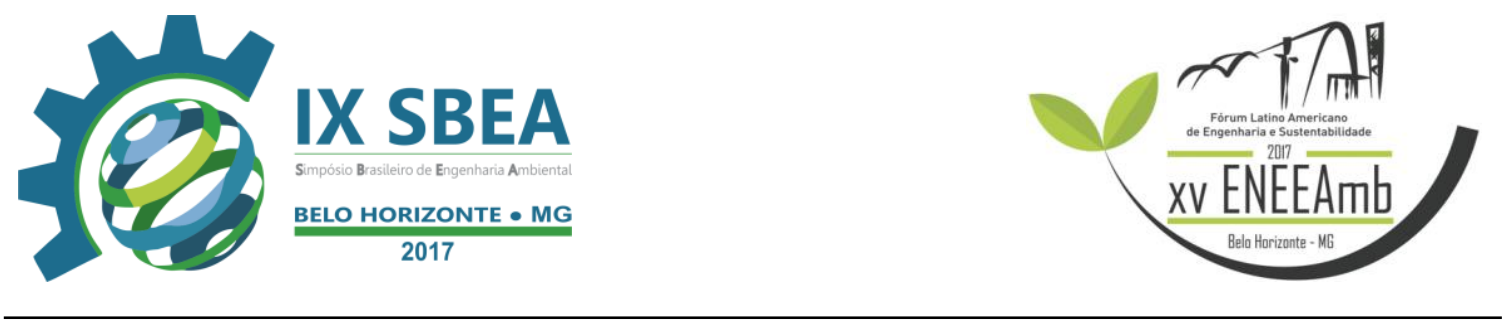

tecido urbano com baixas densidades de ocupação, inviabilizando a implantação de infraestrutura e serviços básicos (SOUZA, SILVA, 2009).

A ocupação espontânea é promovida por iniciativa da população por meio de invasão de terrenos públicos e áreas de preservação permanente (SOUZA, SILVA, 2009). Os loteamentos irregulares ou clandestinos podem ser realizados pelo setor público e pelo setor privado (ARAÚJO, 2009).

Nessa perspectiva, uma das problemáticas mais decorrentes das áreas de ocupação espontânea é a falta de saneamento, principalmente, no que diz respeito as obras estruturais. Por isso, é necessário urbanizar, mas também sanear as áreas que compõem as cidades.

Segundo Tucci et al. (2001) o sistema de drenagem urbana deve ser entendido como o conjunto de infraestrutura existente em uma cidade para realizar a coleta, o transporte e o lançamento final das águas superficiais. E constituído por uma série de medidas que visam minimizar os riscos a que estão expostas as populações, diminuindo os prejuízos causados pelos alagamentos e inundações.

Nesse contexto, o sistema de drenagem é subdividido ainda em duas formas sendo elas:

O sistema de drenagem é composto de dois tipos de intervenções no ambiente em que são classificados em: medidas estruturais e as medidas não estruturais. Sendo a primeira composta de complexidade envolvendo obras hidráulicas para um bom escoamento das águas pluviais melhorando a condição de vazão, deslocamento e despejo nos corpos d'água receptores, mediante a construção de instrumentos como canais, diques e galerias. Já a segunda, as medidas não estruturais são aquelas em que os prejuízos são reduzidos pela melhor convivência da população com as enchentes (MANUAL DE DRENAGEM URBANA, 2012 b).

Portanto, o presente trabalho tem por objetivo analisar e verificar a eficiência do sistema de drenagem urbana de águas pluviais em uma área de ocupação espontânea no município de Ananindeua-PA.

\section{METODOLOGIA}




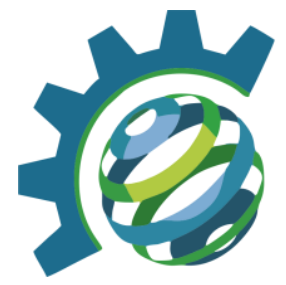

\section{1 Área de Estudo:}

O bairro do 40 (quarenta horas) está localizado na cidade de Ananindeua no Pará, foi originado pelo processo de industrialização na década de 70 (setenta), em que seu processo de ocupação se deu inicialmente pela implantação de madeireiras e somente em 90 (noventa) passou a ter seus primeiros moradores. O nome peculiar do bairro é atribuído em decorrência do rio 40 horas e nos últimos sete anos o bairro vem apresentado alto grau de urbanização devido a construção de condomínios, prédios etc. No entanto, o bairro não fora planejado e por isso apresenta altos déficits de saneamento básico.

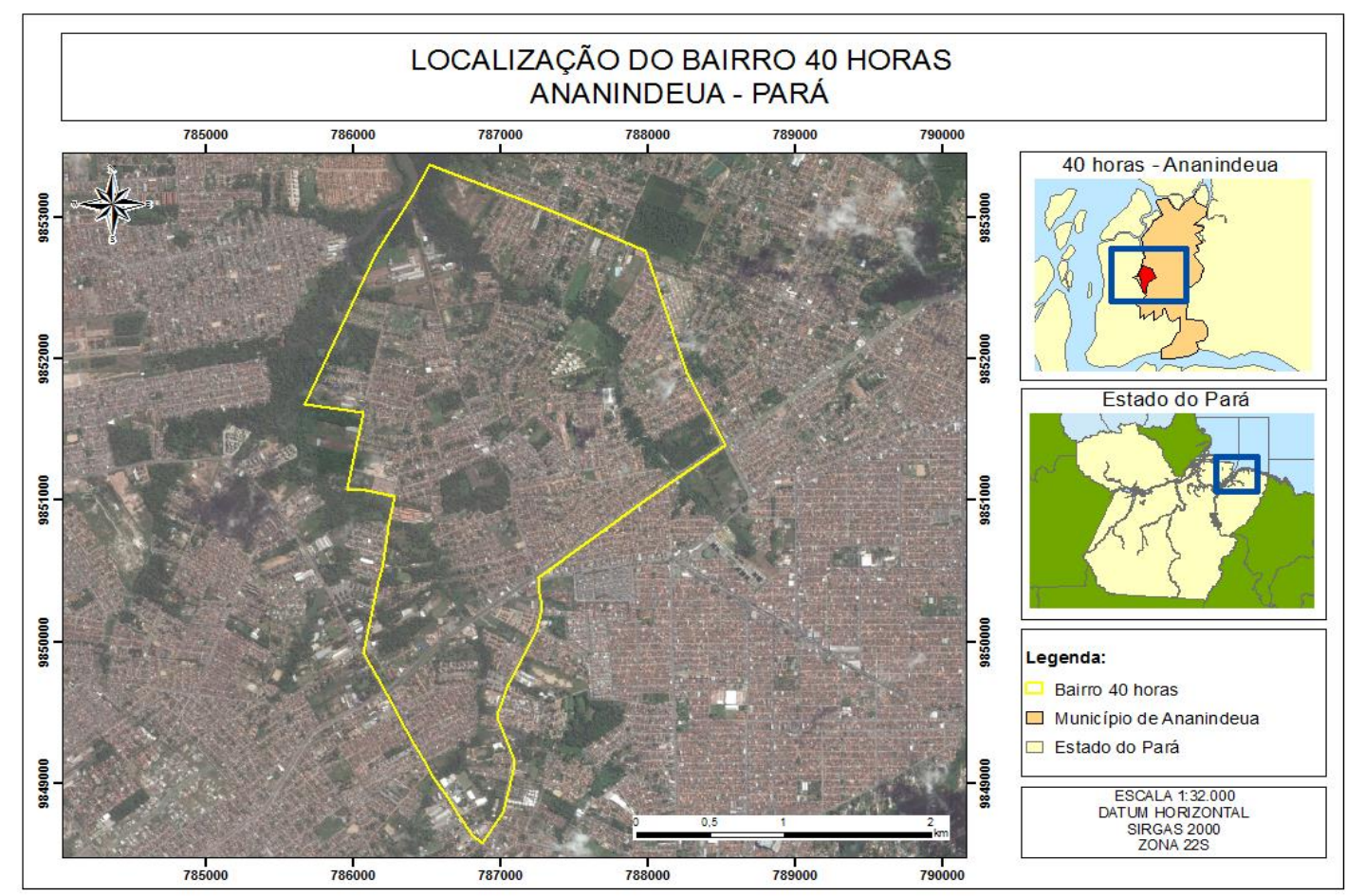

Figura 01. Localização do bairro do quarenta horas, Ananindeua-PA

\subsection{Pesquisa Bibliográfica:}

Para a elaboração deste trabalho foi necessário o levantamento bibliográfico por meio de consultas a artigos, dissertações, livros, monografias, trabalho de conclusão de curso (TCC) e trabalhos científicos que conduziram a uma reflexão teórica sobre conceitos e ideias importantes de autores que tratam da temática de drenagem urbana e sua relação com saúde pública. 


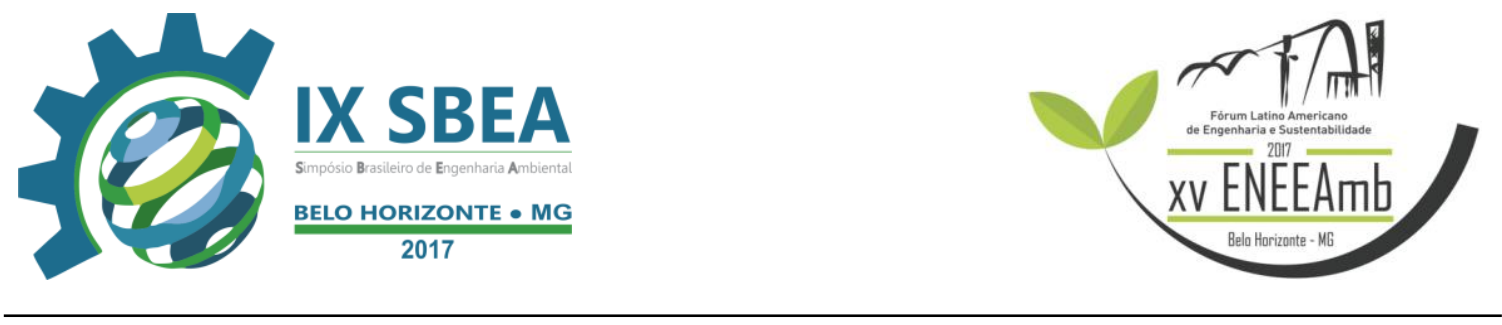

\subsection{Levantamentos de Dados:}

Os levantamentos foram obtidos por meio de indicadores quanti-qualitativos, por meio de um questionário estruturado com perguntas abertas e fechadas aplicado a 130 (cento e trinta) moradores do bairro estudado. Vale ressaltar que, esta entrevista possibilitou o conhecimento sobre o perfil social, econômico e ambiental dos moradores.

\subsection{Análise de Dados:}

Com os dados já coletados pode-se fazer a análise que consistiu em tratamento estatístico simples utilizando o software Excel e tabulação de gráficos. Essa etapa da pesquisa baseou-se na construção da explanação, que conforme Yin (2001) o objetivo é analisar os dados do estudo, construindo uma explicação sobre a realidade estudada.

\section{RESULTADOS E DISCUSSÕES}

A partir dos questionários aplicados à população do bairro do 40 horas foi possível diagnosticar o perfil socioeconômico dos moradores. Nesse sentido, a maioria é composta por pessoas do sexo feminino sendo que não há apenas um gênero predominante considerado como chefe da família, pois todas as residências são bastante heterogêneas (Gráfico 01). Com relação a idade houve um praticamente um equilíbrio entre os estudados, mas pode-se dizer que a maioria é composta por pessoas adultas (Gráfico 02).
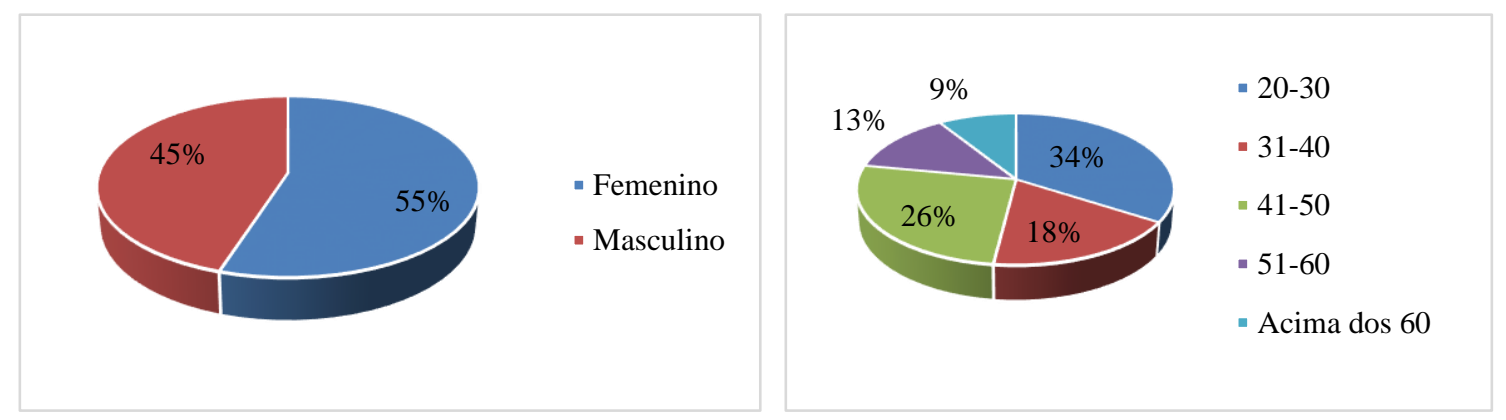

Gráfico 01. Sexo dos Moradores do Bairro Gráfico 02. Idade dos Moradores do Bairro 


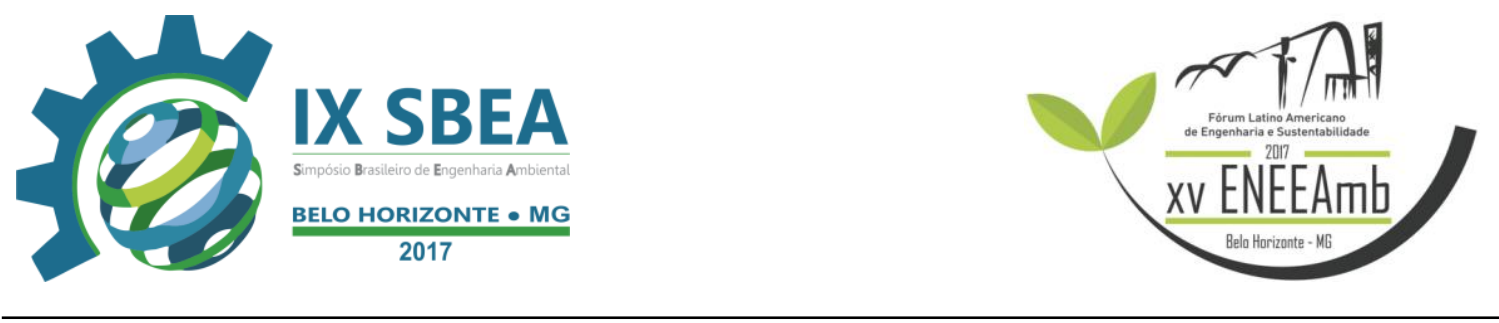

No gráfico 03 observa-se que a maioria dos entrevistados possuem ensino médio completo. A avaliação desses resultados é positiva, pois a educação é um elemento propulsor no desenvolvimento da sociedade, uma vez que, estabelece intima relação com os conhecimentos intelectuais e possibilita uma maior oportunidade de emprego.

Com relação ao rendimento familiar a maioria dos entrevistados relatou ter renda de um salário mínimo. Desta forma, esse indicativo é negativo para o desenvolvimento econômico do bairro, pois é possível inferir que isso acarreta consequências na qualidade de vida das pessoas que precisarão trabalhar mais para obter um nível maior de geração de renda (Gráfico 04).

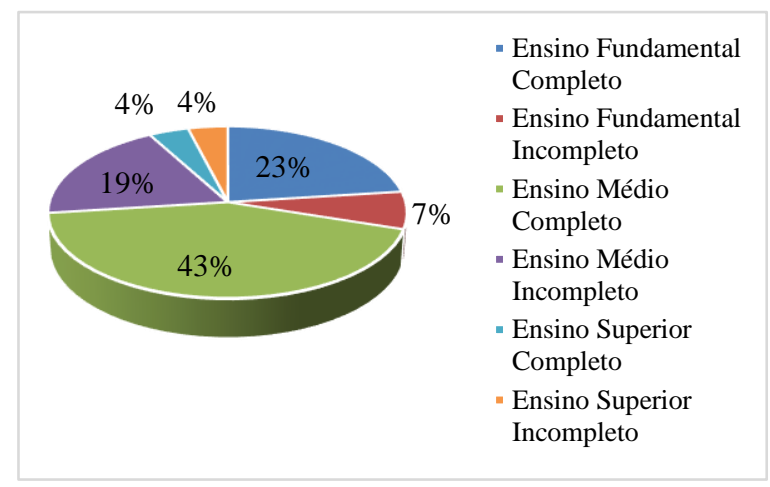

Gráfico 03. Escolaridade dos Moradores do Bairro

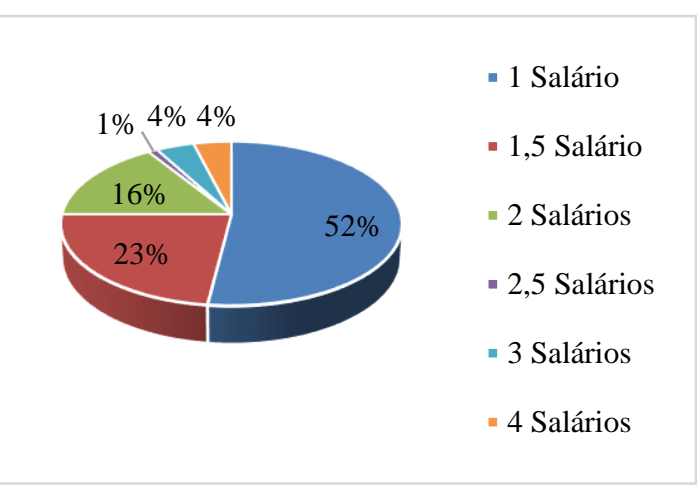

Gráfico 04. Renda Familiar dos Moradores do Bairro

A análise e interpretação dos dados a seguir são do questionário contendo 13 perguntas que avaliam a eficiência do sistema de drenagem urbana por meio das condições estruturais do sistema e seus aspectos operacionais. Este diagnóstico será de grande importância para a formulação das diretrizes básicas para elaboração do plano diretor de drenagem urbana (PDDRU).

Sendo assim, o gráfico (05) apresenta à existência da rede de drenagem de águas pluviais, verifica-se que o bairro apresentou índices positivos para cobertura do sistema. "A microdrenagem inclui a coleta e afastamento das águas superficiais ou subterrâneas através de pequenas e médias galerias" (BOTELHO, 1998).

Sobre a frequência com que há manutenção nas redes, os resultados apontaram uma situação crítica, pois nas redes de microdrenagens não são realizadas reparos e/ou consertos segundo informações dos moradores (Gráfico 06). 


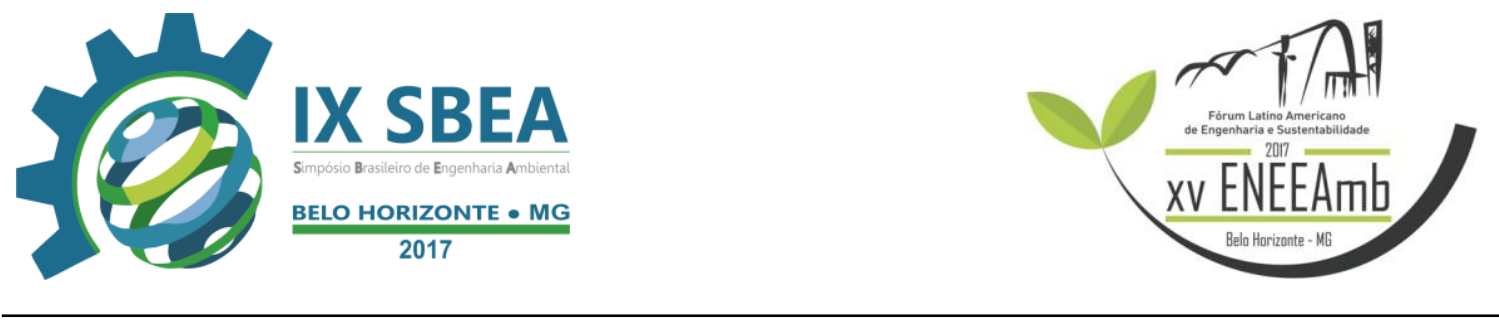

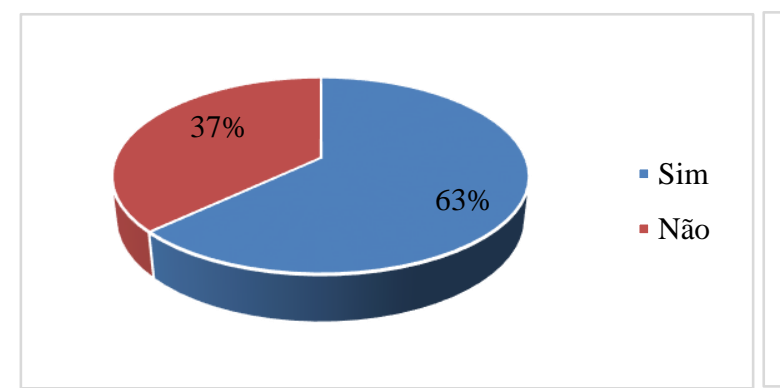

Gráfico 05. Existência da cobertura da rede de drenagem urbana

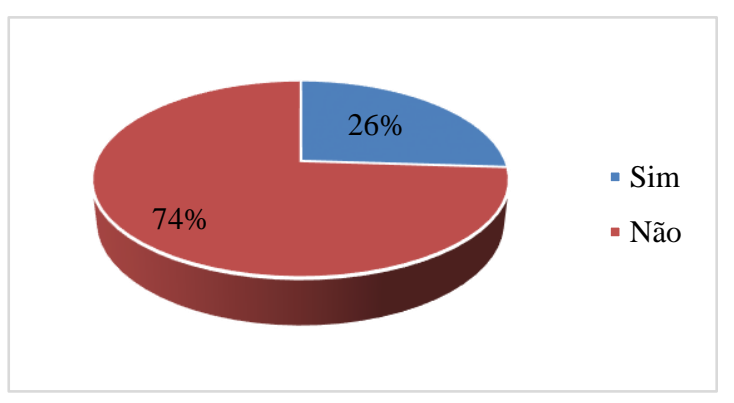

Gráfico 06. Manutenção da cobertura da rede de drenagem urbana

O gráfico sete (07), mostra a relação das estruturas e o funcionamento do sistema de drenagem urbana da área de estudo pelas redes de microdrenagem representada por: pequenas e médias galerias, boca de lobo, ruas pavimentadas, sarjetas e meios-fios responsáveis pela coleta e transporte das águas pluviais até o ponto de lançamento que podem ser os canais, córregos ou rios. Sendo assim, embora o bairro apresente tais sistemas o seu desempenho é precário ou inoperante.

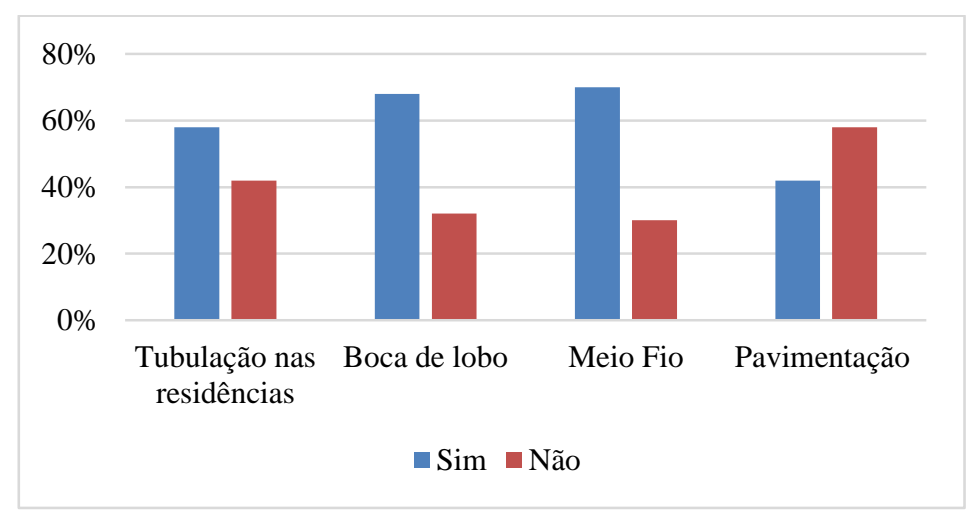

Gráfico 07. Existência das estruturas que compões a rede de drenagem urbana

Durante as visitas de campo foi feito o levantamento das condições de funcionamento do sistema de drenagem para compreender e diagnosticar a realidade sanitária e ambiental do bairro. Constatou-se que das 172 bocas de lobo 13 estavam sem condições de limpeza, 25 sem as tampas e 18 desmoronadas, outras entupidas por acumulo de resíduos. As estruturas estão muito desgastadas pela ação do tempo e/ou pela falta de manutenção. Verificou-se a atividade de limpeza ausente, meios-fios inoperantes, ruas sem recapeamento asfáltico (Figuras 02 ). 

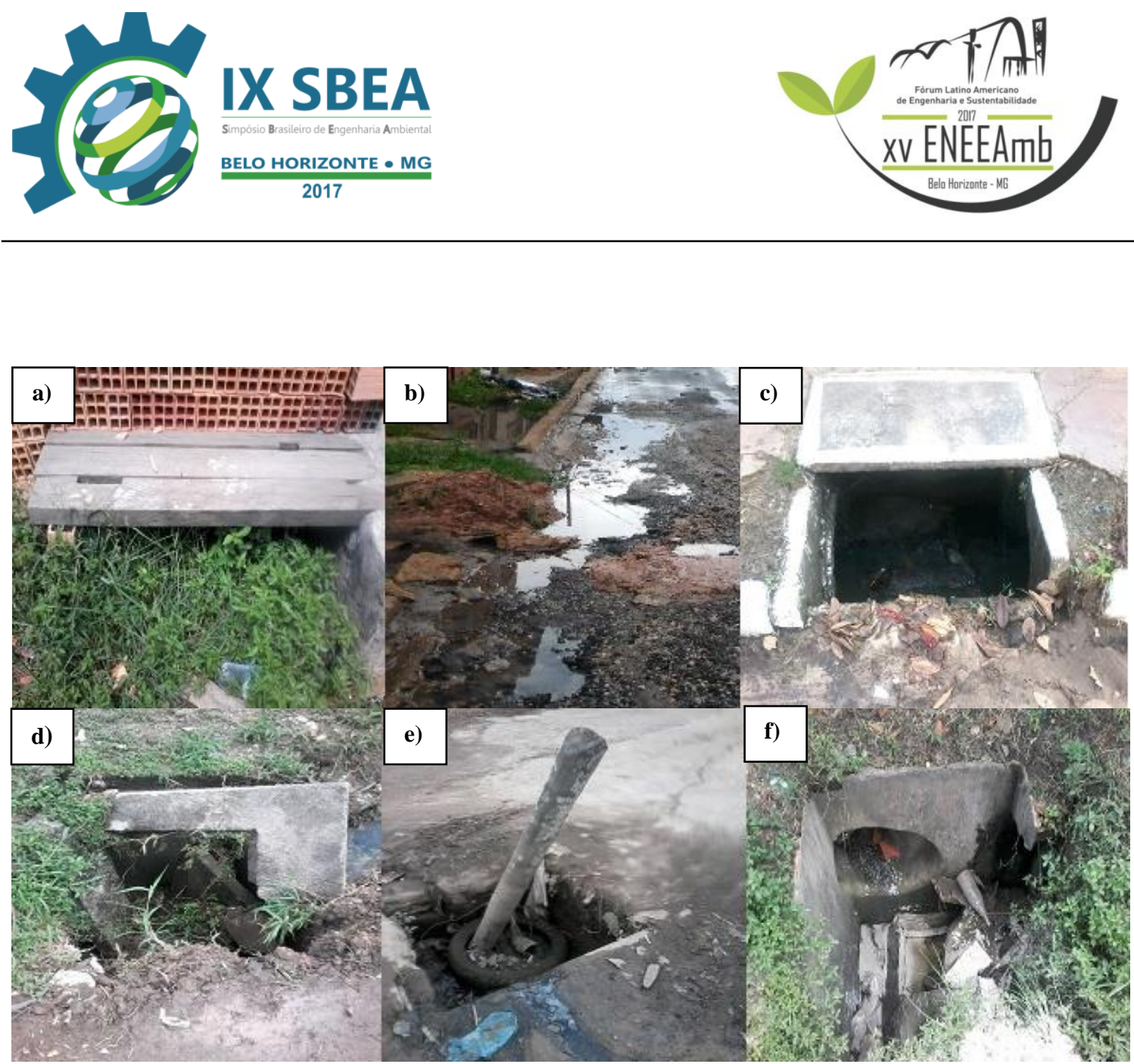

Figura 02. Identificação de problemas estruturais nas bocas de lobo e obstrução da

pavimentação asfáltica

Quando se questionou sobre os alagamentos no bairro, grande parte da população afirmou que é constante esse tipo de ocorrido. Os moradores relataram ainda que chuvas de 30 a 40 minutos são suficientes para encher grande parte das ruas devido o entupimento das bocas de lobo causado pelo descarte inadequado de resíduos sólidos no sistema.

No entanto, a maior parte da população negou despejar seus resíduos nas ruas em horários inapropriados. Outro aspecto abordado foi sobre o conhecimento da população sobre as interferências que os resíduos causam quando destinados de forma incorreta em que, a maioria afirmou saber consequências negativas de descarta-los de forma inadequada (Gráfico 08). 

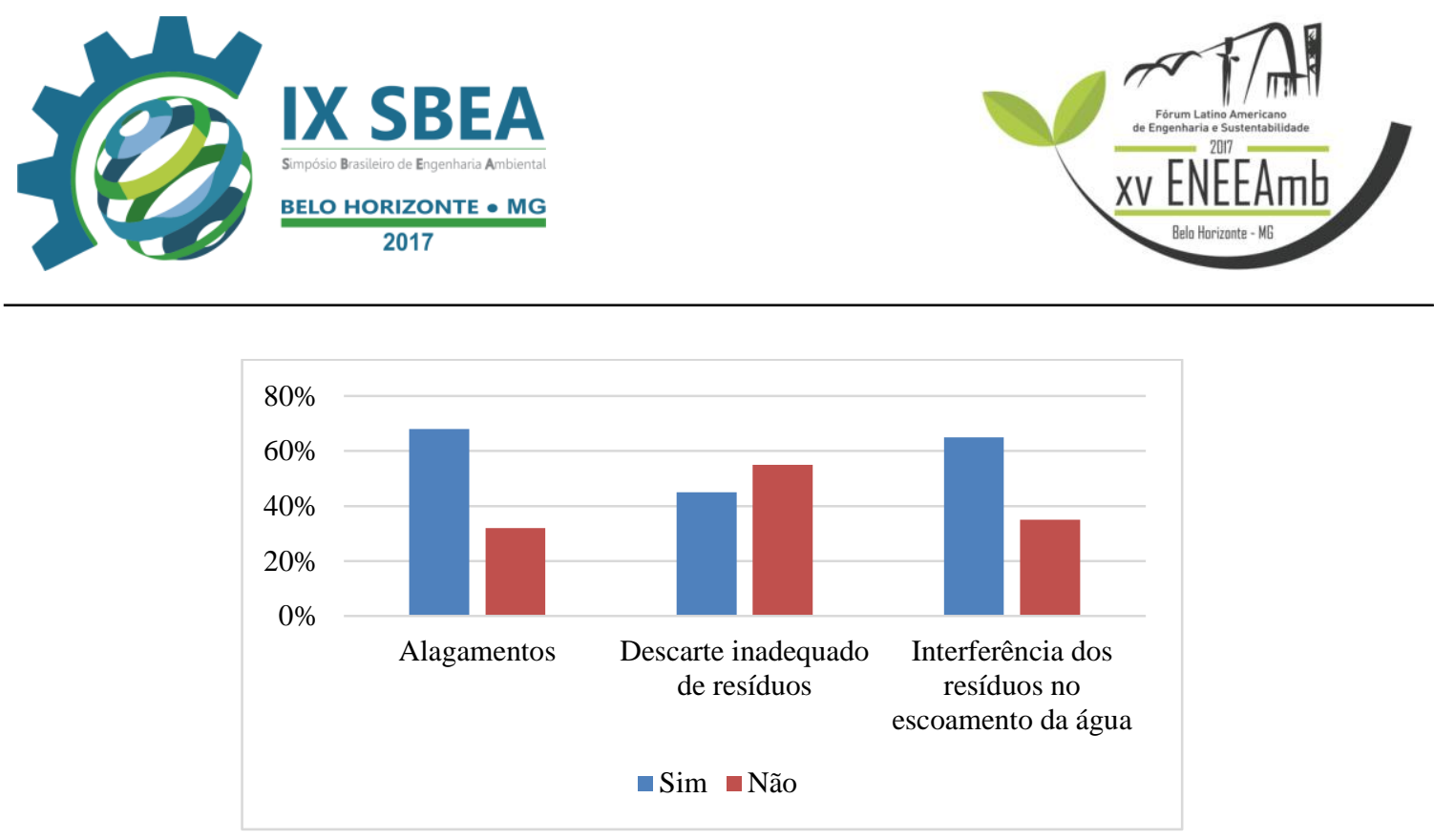

Gráfico 08. Relação de alagamentos, descarte de resíduos e interferências dos resíduos nas redes de drenagem

Entretanto, as respostas obtidas pelos questionários não entram em acordo com pesquisa de campo, porque constatou-se na avaliação das redes de drenagem que grande parte das estruturas estavam com os sistemas comprometidos ou vedados por descarte inadequado de resíduos sólidos como mostra a figura 03 .

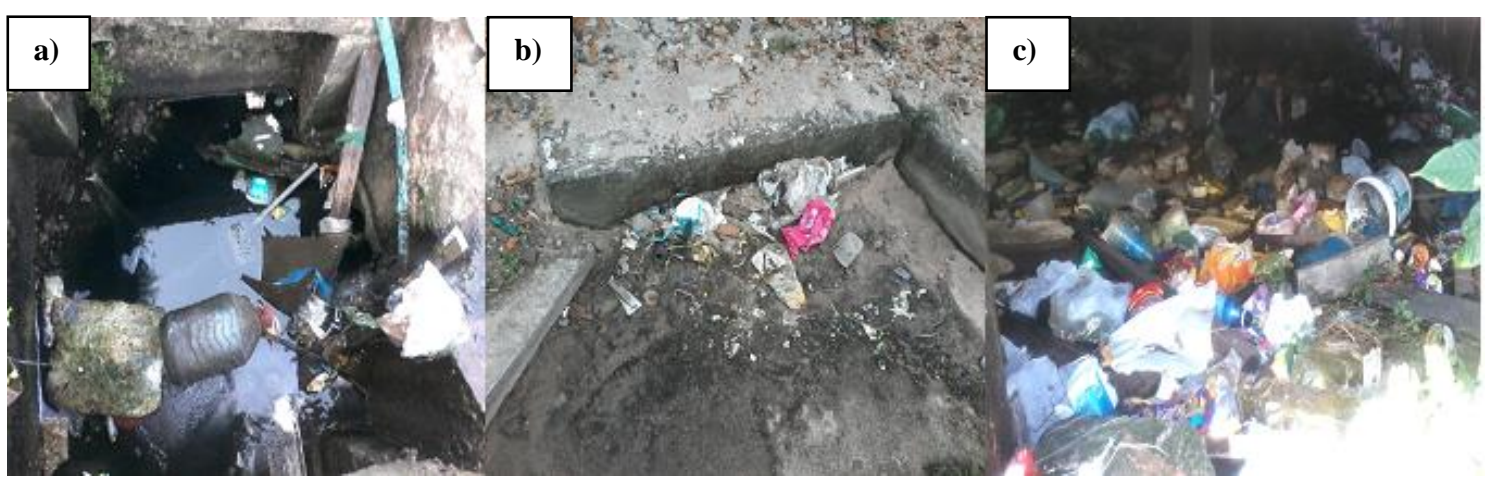

Figura 03. Descarte inadequado de resíduos sólidos nas redes de microdrenagem

De acordo com Almeida \& Costa (2014) existe uma relação drenagem e saúde pública, por isso, a necessidade de intensificação das ações de vigilância em saúde em decorrência da exposição da população aos riscos de doenças em áreas suscetíveis ao risco de alagamentos, principalmente, nas áreas de ressaca, dos efeitos sobre a saúde e investigação epidemiológica de possíveis surtos de doenças, principalmente as de veiculação hídrica.

Nessa perspectiva, o gráfico nove (09) mostra a relação de doenças adquiridas pelos moradores por contanto ou associado a água contaminada. Verificou-se um alto 


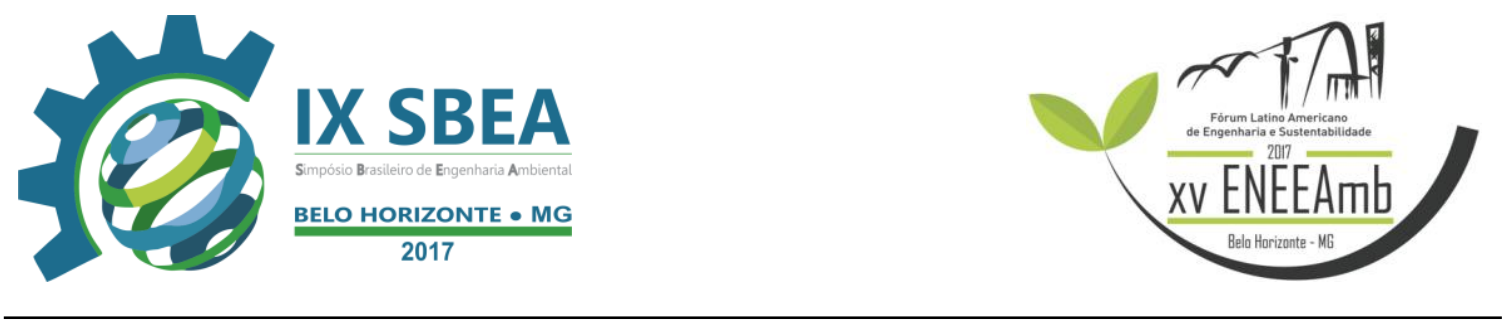

índice de doenças demostrando os riscos eminentes que população sofre com alagamentos e condições desfavoráveis de saneamento básico.

Segundo o Anuário Estatístico do Município de Belém (2012), na cidade foram registrados 2.938 casos de dengue em 2011, sendo esta doença uma preocupação nacional atualmente.

Por fim, quando questionados se a família adotou alguma medida preventiva após acontecimento do surgimento de doenças na família, os moradores relataram esperar a rua alagada secar para sair de casa evitando o contanto com a água suja. Outra medida foi a limpeza do terreno, tubulação nas residências para escoar as águas pluviais, bem como, limpeza pública das ruas para evitar o atrativo a vetores.

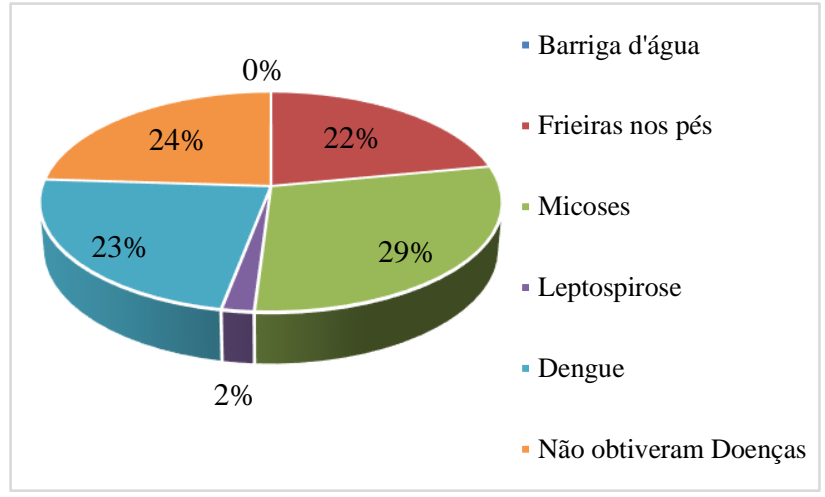

Gráfico 09. Doenças relacionada a precariedade da rede de drenagem urbana

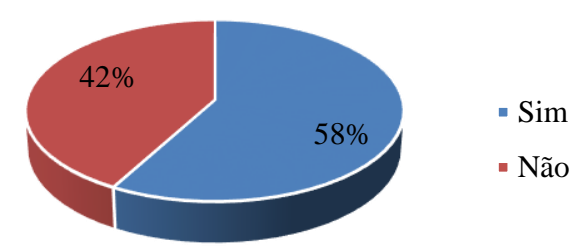

Gráfico 10. Adotou medida de prevenção a doenças

\section{CONCLUSÕES/RECOMENDAÇÕES}

A partir dos dados obtidos mediante a verificação do sistema de drenagem urbana foi possível concluir que o bairro apresenta diversos problemas estruturais o que é comum em áreas de ocupação de espontânea onde geralmente há pouca infraestrutura, ressaltando assim a necessidade de se investir em obras estruturais para os serviços de saneamento básico com ênfase na drenagem urbana.

O estudo demonstrou ainda a insuficiência em quantidade e qualidade dos dispositivos de microdrenagem que apresentaram diversos problemas tais como: bocas de lobo sem tampa, entupidas e desmoronadas. Os meios fios encontram-se em estados precários prejudicando assim o correto funcionamento do sistema. 


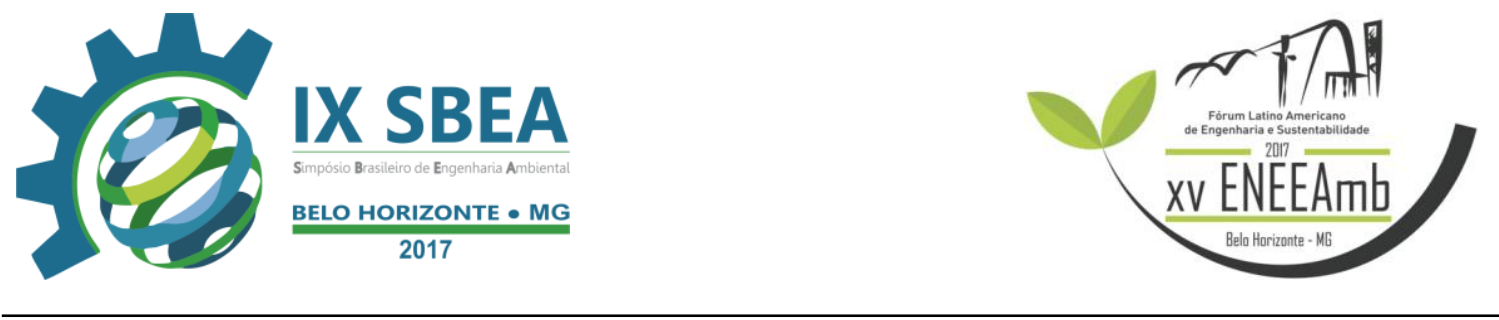

Além disso, a ausência da gestão integrada dos recursos hídricos para escoamento das águas pluviais tem colocado em alerta a saúde dos moradores que por diversas vezes entram em contato com água contaminada devido o déficit da prestação do serviço.

Logo, uma das soluções seria o cumprimento da legislação municipal, o plano diretor urbano, que trata de diversos temáticas como: o uso e ocupação do solo, habitação, legislações ambientais e, por conseguinte, o serviço de drenagem urbana. Adotando esse planejamento de gestão e possível reverter o atual cenário de degradação ambiental, social e econômico que o bairro se encontra.

\section{REFERÊNCIAS BIBLIOGRÁFICAS}

ALMEIDA, D. S de. COSTA, I. T. da. A drenagem urbana das águas pluviais e sua relação com o meio ambiente e a saúde pública no município de Santana. 2014. Trabalho de conclusão de curso- Curso de Bacharelado em Ciências Ambientais, Universidade Federal do Amapá, Macapá, 2014.

ARAÚJO, R. S. Modificações no planejamento urbanístico. Ronaldo de Sousa Araújo - São Paulo: NOBEL, 2009.

BOTELHO, M. H. C. Águas de Chuva: Engenharia das Águas Pluviais nas Cidades. EDGARD BLÜCHER LTDA, $2^{a}$ Ed. rev. e ampl. - São Paulo, 1998.

PLANO DIRETOR DE DRENAGEM URBANA - Manual de Drenagem Urbana Volume VI. 2005.Disponívelem: $<$ http://lproweb.procempa.com.br/pmpa/prefpoa/dep/usu_doc/manu al_de_drenagem_ul tima_versao.pdf $>$. Acesso em: 20 de Ago de 2016.

PREFEITURA MUNICIPAL DE BELÉM. Anuário Estatístico do Município de Belém. $2012 . \quad$ Disponível em $\langle$ http://www.belem.pa.gov.br/app/c2ms/v/?id=2\&conteudo=4485 $>$. Acesso em 15 mar. de 2017.

SOUZA, F. P., SILVA, J. A, F. Estudo de Ocupação Espontânea na Lagoa do Vigário, no Município de Campos dos Goytacazes - RJ, propostas mitigadoras e amparo legal - Boletim do observatório Alberto Ribeiro Lamego, V. 3, n² (2009).

TUCCI, C.E.M.; MARQUES, D.M.L.M. Avaliação e Controle da Drenagem Urbana. Porto Alegre. Editora ABRH, 1a edição: 2001 vol. 2, p. 548. 